\title{
RELAÇÕES ENTRE HUMOR E PODER: UM COMENTÁRIO CRÍTICO SOBRE A OBRA “FOI-SE O MARTELO. A HISTÓRIA DO COMUNISMO CONTADA EM PIADAS", DE BEN LEWIS.
}

\section{RELATIONSHIPS BETWEEN HUMOR AND POWER: A CRITICAL COMMENTARY ON THE PLAY "GONE IS THE HAMMER. THE STORY OF COMMUNISM TOLD IN JOKES "BY BEN LEWIS.}

\author{
Cellina Rodrigues Muniz (UFRN) ${ }^{1}$
}

Quando se fala em Comunismo - e no modo como este foi implantado nos países do chamado Bloco Soviético - , certamente não é em humor que se pensa de imediato. Mas, ao contrário do que possa sugerir a atmosfera terrificante dos regimes da Cortina de Ferro, o livro do jornalista britânico Ben Lewis (2014) vem mostrar que o sistema políticoeconômico inspirado em Marx, Engels, Lênin e Trotsky foi terreno fértil para a criação e proliferação anônima e profícua de textos humorísticos: das anedotas caricatas sobre os líderes (Lênin, Stálin, Ceauşescu, etc.) às piadas subversivas sobre modos de vida nos países socialistas com seus principais "aparelhos" (o Sputnik, a Stasi, a Cheka, o Pravda etc.), o humor foi, sem dúvida, um importante legado do cenário instaurado a partir do Outubro Vermelho dos Bolcheviques.

Lançado em 2008 (no Brasil, em 2014), com o título original Hammer and Tikle literalmente, "Foice e Cócegas", um trocadilho para Hammer and Sikle, isto é, "Foice e Martelo" - e ao longo de nove capítulos e 430 páginas, o livro de Lewis é um ótimo exemplo para demonstrar algumas teses que tratam das interfaces discurso-poder, ainda que esse não seja o foco do trabalho de Lewis. Durante toda a leitura, fica evidente como o humor pode ser tomado como uma prova contundente de várias teses discursivas, como, por exemplo, a interdiscursividade (notadamente por meio da polêmica) e, sobretudo, de que textos chistosos ilustram a linguagem, em seu caráter discursivo, como uma arena de vozes (BAKHTIN, 1986), um verdadeiro campo de caráter bélico marcado por posicionamentos controversos (MAINGUENEAU, 2011)2. Comentaremos algumas partes desse livro.

Já na introdução, o tom do autor dá a medida do que se esperar do livro: entre o pessoal e o documental, o jornalístico e o acadêmico, Lewis revela de maneira informal as trilhas de sua pesquisa e aos poucos faz o leitor entrever a luta (das armas de fogo às sutis propagandas) que o sistema comunista/socialista travou para se impor ao resto do mundo polarizado do século XX.

No capítulo "O riso sob o regime de Lênin" o autor demonstra como certa tradição literária funcionou, ainda na Rússia tzarista, como solo para que frutificassem os primeiros textos a satirizar o governo logo após a Revolução. Como uma espécie de mapeamento das condições de possibilidade (para fazer uso de uma expressão foucaultiana) para a criação e circulação de piadas de comunismo, Ben Lewis faz um rápido levantamento de alguns autores e obras satíricas das décadas de 1920 e 1930, tais como Mikhail Bulgakov, Yevgeny

\footnotetext{
1 Professora Doutora do Departamento de Letras e do Programa de Pós-Graduação em Estudos da Linguagem da Universidade Federal do Rio Grande do Norte. Doutora em Educação (UFC) com PósDoutorado em Linguística (UNICAMP).E-mail: cellina979164@gmail.com

2 Possenti $(1998,2010)$, a esse respeito, defende que textos de humor são, tematicamente, necessariamente polêmicos, ilustrando assim um conflito entre visões de mundo distintas.
} 
Zamyatin e Mikhail Zoshchenko, autores esses, inclusive, já amplamente difundidos em outros países ${ }^{3}$. Embora não aborde esse aspecto, fica evidente, nesse capítulo, como o humor converge, em culturas letradas, com os campos discursivos da literatura e da imprensa ${ }^{4}$. Para fechar o capítulo, como não poderia deixar de ser ao se pensar a relação (contestadora ou não) entre comunismo e literatura, o autor apresenta uma piada sobre o poeta Maiakovski, importante entusiasta do regime. Após seu suicídio, já desiludido com os rumos da Revolução Vermelha, nem mesmo ele escapou às línguas afiadas que, em surdina, cochichavam:

Quais foram as últimas palavras de Maiakovski antes de cometer suicídio? “Camaradas, não atirem!” (LEWIS, 2014, p. 75).

No capítulo intitulado "Stalin e o sorriso macabro", o autor apresenta uma série de anedotas a respeito do ditador que indicam uma estrutura binária a caracterizar um humor peculiar: o reconhecimento irônico da violência de sua dominação seguida da conclusão de sua magnanimidade (p. 78), o que podemos atrelar esse tipo particular de piadas ao que Propp (1992, p. 159) designou "riso cínico". Essa peculiaridade, por outro lado, confirma uma dinâmica universal do discurso humorístico: a quebra de expectativas e o confronto entre esquemas de raciocínio diferentes (lógico/ilógico; normal/anormal; perverso/benevolente) é o que pode gerar um efeito de riso (cf. RASKIN, 1985), tal como ilustra a seguinte piada (LEWIS, 2014, p. 79):

Stálin está fazendo um discurso a uma assembleia de trabalhadores numa grande fábrica. "O que mais prezamos na União Soviética é a vida humana", diz ele.

De repente, alguém tosse.

“Quem está tossindo?”, pergunta Stalin.

Silêncio.

“Tudo bem, chamem o NKVD”, diz o ditador.

A polícia política de Stalin chega disparando suas armas semiautomáticas. Logo só restam sete homens em pé. Stalin pergunta de novo: "Quem tossiu?"

Um homem levanta a mão.

"Você está com uma gripe terrível", diz Stalin. "Pegue meu carro e vá ao hospital".

Ainda nesse mesmo capítulo, uma indagação que Lewis faz sugere a constituição circular entre enunciados e enunciação: "Como se poderia interpretar o fato de que Stalin ria do mesmo tipo de piada que seus inimigos estavam cochichando? O problema é que ninguém sabia o que tinha vindo primeiro, as piadas cruéis de Stalin ou as piadas sobre o cruel Stalin" (LEWIS, 2014, p. 80). Em outras palavras: da mesma maneira como enunciados se constituem a partir de determinadas condições de enunciação, eles também legitimam e revitalizam tais condições.

\footnotetext{
${ }^{3}$ Ver, por exemplo, a antologia organizada por Gomide (2011).

${ }^{4}$ A esse respeito, ver, por exemplo, alguns trabalhos que se detêm, no contexto brasileiro de início da República, sobre jornais e revistas humorísticas, dos quais cito apenas dois: Saliba (2008) e Lustosa (1993).
} 
O fato é que esse terrível período (até o ano de 1952, pouco antes da morte de Stalin, 2,5 milhões de pessoas foram mandadas para os Gulag, os campos de concentração stalinistas) foi marcado por aquilo que se pode chamar de "piada de cadafalso", aquele tipo de humor que, baseado no riso da própria desgraça e rebaixamento, numa perspectiva freudiana, funciona como uma espécie de defesa psíquica.

Nessa lógica de autoderrisão, por exemplo, a fome era um tema recorrente. Basta recordarmos, a esse propósito, do inverno de 1932-1933 na Ucrânia, em que milhões de pessoas foram deixadas à míngua num triste episódio conhecido como a Grande Fome. Mesmo nesse clima de genocídio, piadas como essa chegaram a circular:

Duas velhinhas famintas conversam numa aldeia. Uma delas vê uma lesma. "Olhe, rápido", diz uma delas. "Temos algo para comer, uma lesma". A outra tenta pegar a lesma, mas não consegue. "Foi rápida demais para mim", ela diz, decepcionada (LEWIS, 2014, p. 325).

A tentativa de rir de si como estratégia psíquica de defesa pode ser atestada pelo seguinte relato de Lev Razgon, que sobreviveu a 17 anos num Gulag durante o Grande Terror (LEWIS, 2014, p. 97):

Usávamos todos os meios para disfarçar o medo, para empurrá-lo para bem fundo. Nós brincávamos sobre isso, contávamos histórias engraçadas, e em nossas conversas particulares "eles" pareciam não apenas cruéis, mas também idiotas.

A subversão de papéis do mundo "normal" - em que um personagem é destituído do papel de soberano para se tornar um simples tolo - remete à uma cosmovisão carnavalesca de mundo, pautada, dentre outros aspectos, na quebra das hierarquias (BAKHTIN, 1987). O mesmo se vê, por exemplo, no caso do ditador romeno Nicolae Ceauşescu e sua esposa Elena, apresentados em inúmeras piadas como objetos de zombaria. À revelia das festividades e discursos oficiais que mostravam o casal de maneira grandiloquente, o aspecto cômico do tirano ("baixinho, sem graça, gago, decrépito") sugeria piadas anônimas que corriam na clandestinidade, tais como esta (LEWIS, 2014, p. 323):

Um painel com os melhores comediantes romenos será pintado na fachada do Teatro Nacional de Bucareste. No meio deles estarão representados, é claro, Nicolae e Elena Ceauşescu.

Dentro do amplo espectro de elementos que a relação entre humor e poder suscita, Lewis mostra como esses exemplos refletem também a relação humor-subversão, relação essa que pode estar atrelada a uma das três grandes teses sobre humor que o livro traz: uma tese minimalista, isto é, o humor como forma de aliviar a pressão; uma tese maximalista, ou seja, o humor como revolucionário, no sentido de ir minando aos poucos o regime; e por fim uma tese negadora, que atribui ao hábito de contar piadas "a falsa impressão de estarem lutando contra o sistema" (LEWIS, 2014, p. 221).

Outro capítulo que merece destaque é o que trata das revistas satíricas publicadas na Alemanha oriental (“A idade de ouro das piadas de comunista”) e que exemplifica a relação entre humor, censura e resistência por meio de um gênero discursivo clássico: as charges. Tais publicações, muitas delas clandestinas - as samiz̨dat - (com exceção da revista Eulenspiegel, que era relativamente aceita pelo governo, mas que ainda assim chegou a ter várias edições recolhidas) apelaram para a chacota com temas recorrentes, como a corrupção do Estado socialista, as filas intermináveis, a tentativa dos governos socialistas de 
moldar "realidades" por meio da mudança de nomes e a falsa grandiosidade de sua indústria.

A respeito desse último tema, por exemplo, pode ser citada uma charge que representa a entrega de uma casa por um membro do governo para uma família operária (p. 233): o personagem diz “... é com grande prazer que eu agora lhes entrego a chave de sua nova casa" e o que o desenho mostra é uma chave-inglesa, a sugerir, por meio do procedimento chistoso da condensação (também conhecido como "duplo sentido", cf. FREUD, 1987), que serão necessários reparos para a construção malfeita.

Um último ponto a ser ressaltado na pesquisa de Lewis fica por conta de momentos literários de verdadeiro primor: a relação amorosa entre o pesquisador e a informante alemã ou a ligeira digressão que o narrador Lewis faz, no relato de suas andanças e buscas, ao realizar uma paródia impagável do desenho americano Os Simpsons para representar o modo de vida das famílias dos países socialistas - Os Zimpsonoviches. Famílias desiludidas com o que se pôs em prática efetivamente em termos de utopia comunista e que culminaram em piadas como esta (LEWIS, 2014, p. 372):

É verdade que, quando chegarmos ao comunismo pleno, não haverá mais piadas políticas? Sim, exceto esta.

Do livro de Ben Lewis, baseado em diversos tipos de fontes (revistas satíricas, documentos oficiais, antologias de piadas, relatos orais etc.), pode-se concluir que a relação entre humor e comunismo não é lisa e homogênea. Como ele mesmo afirma,

Há piadas demais para serem englobadas numa definição universal, e há tradições de humor diferentes demais que influenciaram as piadas sobre comunismo - da anedokt tzarista, do folclore camponês russo, do humor judeu, das espirituosidade de cada país do Bloco Soviético e do ancestral gênero do humor negro (LEWIS, 2014, p. 217).

O fato é que se trata de um importante registro que reflete não só a máxima de Foucault (2009, p. 105) - lá onde há poder, há resistência - ou do preceito aristotélico de que rir e fazer rir são uma condição humana: trata-se, antes, de uma obra que certamente interessa a historiadores, cientistas sociais, analistas do discurso e todos os demais preocupados em não esquecer o legado do século XX - permeado de totalitarismos tanto à esquerda como à direita. É preciso não esquecer e resistir a todas as formas de opressão, numa resistência que se dá sobretudo por meio do riso, tão necessário nestes tempos atuais de retrocessos políticos no Brasil e no mundo.

\section{Referências}

BAKHTIN, M. Marxismo e filosofia da linguagem. São Paulo: Hicitec, 1986.

A cultura popular na Idade Média e no Renascimento: o contexto de François Rabelais. São Paulo: Hucitec; Brasília: EdUnB, 1987.

FOUCAULT, M. A bistória da sexualidade 1: a vontade de saber. 19ª ed. Rio de Janeiro: Graal, 2009. 
FREUD, S. Os chistes e sua relação com o inconsciente. Obras completas de Sigmund Freud. Volume VIII. 2ed. Rio de Janeiro: Imago, 1987.

GOMIDE, B. B. 2011. Nova Antologia do Conto Russo (1792-1998). São Paulo: Editora 34.

MAINGUENEAU, D. 2011. Doze conceitos em Análise do Discurso. São Paulo: Parábola Editorial.

LEWIS, Ben. Foi-se o martelo. A história do comunismo contada em piadas. Tradução de Márcio Ferrari. Rio de Janeiro: Record, 2014.

LUSTOSA, I. Brasil pelo método confuso: humor e boemia em Mendes Fradique. Rio de Janeiro: Bertrand Brasil, 1993.

POSSENTI, S. 1998. O bumor das linguas. Campinas, SP: Mercado de Letras. 2010. Humor, língua, discurso. São Paulo: Contexto.

PROPP, Vladimir. Comicidade e riso. Tradução de Aurora Fornoni Bernardini e Homero Freitas de Andrade. São Paulo: Ática, 1992.

RASKIN, V. Semantic mechanisms of humor. Dordrecht: D. Riedel, 1985.

SALIBA, E. T. 2008. Raízes do Riso. A representação humorística na história brasileira: da Belle époque à Era do Rádio. São Paulo: Companhia das Letras.

Submetido em 19/02/2018

Aceito em 14/04/2018 